\title{
Incidence of pneumonia in nursing home residents with dementia in the Netherlands: an estimation based on three differently designed studies
}

\author{
T. P. ZOMER ${ }^{1,2}$, T. VAN DER MAADEN ${ }^{3}$, A. B. VAN GAGELDONK-LAFEBER ${ }^{1}$, \\ S. C. DE GREEFF ${ }^{1}$, J. T. VAN DER STEEN ${ }^{4,5} \dagger$ AND L. VERHOEF ${ }^{1} \dagger^{*}$ \\ ${ }^{1}$ Centre for Infectious Disease Control (CIb), National Institute for Public Health and the Environment \\ (RIVM), Bilthoven, the Netherlands \\ ${ }^{2}$ Lyme Center Apeldoorn, Gelre Hospital, Apeldoorn, the Netherlands \\ ${ }^{3}$ Centre for Health Protection, National Institute for Public Health and the Environment (RIVM), Bilthoven, the \\ Netherlands \\ ${ }^{4}$ Department of Public Health and Primary Care (PHEG), Leiden University Medical Center (LUMC), Leiden, \\ the Netherlands \\ ${ }^{5}$ Department of Primary and Community Care, Radboud university medical center, Nijmegen, the Netherlands
}

Received 7 April 2017; Final revision 1 June 2017; Accepted 5 June 2017;

first published online 3 July 2017

\section{SUMMARY}

Pneumonia leads to considerable morbidity and mortality in nursing home residents with dementia. We assessed pneumonia incidence based on data from three different studies: (1) realtime national surveillance of healthcare-associated infections in nursing home residents in 20092015; (2) a randomized controlled trial in 2012-2015 to assess effects of a practical guideline in nursing home residents with dementia and pneumonia; and (3) a study in 2007-2010 to assess quality of dying in newly admitted nursing home residents with dementia. In national surveillance data, pneumonia incidence was calculated separately for psychogeriatric and somatic beds, as a proxy for residents with and without dementia. Weekly pneumonia incidence was significantly lower per 1000 psychogeriatric beds $(3 \cdot 9$; 95\% confidence interval (CI) $3 \cdot 2-4 \cdot 6$ ) compared with 1000 somatic beds $(5 \cdot 7 ; 95 \%$ CI 5·1-6·3). Annual incidence per 1000 psychogeriatric beds was similar in national surveillance (range 78.9-117.1) and the trial (range

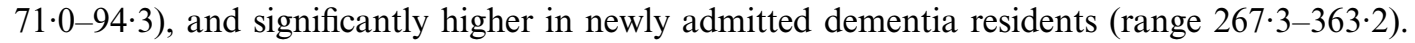
The incidence was highest during the first months after admission when compared with residents with longer stay. In conclusion, follow-up of pneumonia in newly admitted dementia residents may result in higher incidence, possibly due to higher risk in this population.

Key words: Dementia, incidence, nursing home, pneumonia.

\section{INTRODUCTION}

Healthcare-associated infections (HAI) are a significant health problem in nursing homes. Older people

\footnotetext{
* Author for correspondence: L. Verhoef, National Institute for Public Health and the Environment (RIVM), Postbak 75, PO Box 1, 3720 BA Bilthoven, the Netherlands.

(Email: linda.verhoef@rivm.nl)

$\uparrow$ The last authors contributed equally to this study.
}

are at increased risk for HAI because of ageing of the immune system, chronic diseases, polypharmacy, malnutrition, and functional impairments (e.g. diminished cough reflex) [1]. HAI in nursing home residents are associated with mortality, hospital admission, and a reduction in overall physical condition [2]. In Europe, respiratory tract infections, including pneumonia, were found to be the most common HAI in long-term care facilities, although the reported 
prevalence differs substantially between countries [3]. Other common HAI in nursing homes are gastroenteritis, influenza-like illness, urinary tract infections, and skin infections $[4,5]$.

Pneumonia is being recognized as a significant health problem in nursing home residents in general, including those with dementia. Pneumonia and cardiovascular disease are commonly reported as a primary cause of death [6-10]. Pneumonia may contribute substantially to discomfort in nursing home residents with dementia [11], e.g. by causing dyspnea and pain [12]. Moreover, pneumonia increases risk of mortality in residents with dementia compared with residents without dementia [13]. In this perspective, the occurrence of pneumonia has been posited as a reason to consider advanced dementia as a terminal disease for which comfort or palliative care is an appropriate approach, i.e. preferred over burdensome interventions for which the health outcome is questionable given the life expectancy [14]. In the Netherlands, there is a trend toward a higher number of treatments to relief symptoms and to lower discomfort among nursing home residents with dementia $[12,15]$. However, death from pneumonia or a respiratory tract infection may still involve more pain, shortness of breath and agitation [16], and suffering [17] than death from other causes, such as dehydration or cachexia or cardiovascular disease.

Timely recognition of pneumonia can promote a swift response with care focused on symptom relief. In the Netherlands, the occurrence of HAI, including pneumonia, in long-term care facilities has been investigated in several point prevalence studies. For example, in 2010, an overall prevalence of HAI (including gastrointestinal infections, urinary tract infections, systemic infections, respiratory tract infections) in Dutch nursing homes of $2 \cdot 8 \%$ was found in a nation-wide study [18]. In addition, the yearly prevalence of HAI in nursing homes in a certain region in the Netherlands ranged from $6 \cdot 7-7 \cdot 6 \%$ between 2007-2009 [19]. The most prevalent HAI was urinary tract infection (overall prevalence $3 \cdot 8 \%$ ), followed by pneumonia with an overall prevalence of $1 \cdot 6 \%$ [19]. The point prevalence of pneumonia measured in May and June 2010 in 10 Dutch nursing homes was $6 \cdot 1 \%[18,20]$. The pathogens that are found to predominantly cause nursing home-acquired pneumonia are Streptococcus pneumoniae, Staphylococcus aureus, Pseudomonas aeruginosa, and Klebsiella pneumoniae $[21,22]$.
Although several HAI prevalence studies have been conducted in the Netherlands, these studies do not inform on incidence of pneumonia among nursing home residents in general, or among those with dementia specifically. Other than prevalence, where illness is measured at one point in time, the incidence provides insight into the number of newly infected cases and thereby the societal burden of a specific illness at population level. If measured on a continuous basis, the incidence also provides figures about seasonal trends and trends over time.

Incidence data were available from three studies among nursing home residents in the Netherlands [23-25]. The aims and designs of these studies differed. However, the data collected allow for calculations and comparison of pneumonia incidences. The objective of the here described study was to assess the incidence of pneumonia and to identify methodological factors influencing incidence figures in nursing home residents, which can be taken into account in future studies and surveillance programs.

\section{METHODS}

Three different studies with data on pneumonia among residents of nursing homes, including those with dementia, were used to calculate the yearly incidence of pneumonia in nursing home residents. Study design characteristics are detailed in Table 1.

\section{Studies}

The first study concerned the Dutch national surveillance of HAI in nursing homes from 2009 until 2015 (Dutch acronym: SNIV) [25]. The aim of this surveillance was to provide systematic year-round data on the incidence of various infections in Dutch nursing homes for local interventions and national policymaking and for the development of infection control guidelines for the nursing home setting. The assessment of the included infections was based on clinical diagnoses conform medical practice in the nursing home setting, as agreed upon by elderly care physicians [4]. Infections were weekly collectively reported. For pneumonia, the definition was based on previous research on pneumonia in elderly [26, 27] (Table 1). In addition to pneumonia, the following other outcome measures were assessed: gastroenteritis, influenza-like illness, urinary tract infections and mortality.

The second study was a randomized controlled trial, called the PneuMonitor trial, which was 
Table 1. Study design characteristics of three Dutch national studies in nursing home residents

\begin{tabular}{|c|c|c|c|}
\hline & National surveillance [25] & PneuMonitor trial [24] & DEOLD study [23] \\
\hline Time period & January 2009 to December 2015 & January 2012 to May 2015 & $\begin{array}{l}\text { January } 2007 \text { to July } 2010 \text { (survival } \\
\text { up to summer 2011) }\end{array}$ \\
\hline Study objective & $\begin{array}{l}\text { To provide systematic year-round } \\
\text { surveillance data on the incidence } \\
\text { of various infections in Dutch } \\
\text { nursing homes }\end{array}$ & $\begin{array}{l}\text { To assess the effects of the } \\
\text { introduction of a practice } \\
\text { guideline on discomfort and } \\
\text { symptoms following the diagnosis } \\
\text { of pneumonia }\end{array}$ & $\begin{array}{l}\text { To describe quality of dying } \\
\text { (including symptom burden) and } \\
\text { satisfaction with care at the end of } \\
\text { life, and factors associated with } \\
\text { these outcomes }\end{array}$ \\
\hline $\begin{array}{l}\text { Nursing home } \\
\text { recruitment }\end{array}$ & Nationwide & Nationwide & Nationwide \\
\hline $\begin{array}{l}\text { Departments/ } \\
\text { wards }\end{array}$ & $\begin{array}{l}\text { Somatic (for people with physical } \\
\text { handicaps), rehabilitation, and } \\
\text { psychogeriatric (almost all } \\
\text { dementia) wards }\end{array}$ & Psychogeriatric wards & Psychogeriatric wards \\
\hline $\begin{array}{l}\text { Resident } \\
\text { inclusion }\end{array}$ & $\begin{array}{l}\text { Collectively - all residents resided } \\
\text { in participating nursing homes } \\
\text { during the study period, while } \\
\text { assuming a } 100 \% \text { coverage of } \\
\text { nursing home beds }\end{array}$ & $\begin{array}{l}\text { Collectively - all residents with } \\
\text { dementia resided in participating } \\
\text { nursing homes during the study } \\
\text { period, while assuming a } 100 \% \\
\text { coverage of nursing home beds. } \\
\text { Additionally, we retrospectively } \\
\text { solicited for any missed enrolment } \\
(22 \cdot 5 \% \text {; } 135 / 599 \text { pneumonia } \\
\text { episodes included) }\end{array}$ & $\begin{array}{l}\text { Individually - residents with } \\
\text { dementia who were newly } \\
\text { admitted to a psychogeriatric } \\
\text { ward of a participating nursing } \\
\text { home up to } 2009 \text { and for whom } \\
\text { the family was willing to complete } \\
\text { questionnaires as well }\end{array}$ \\
\hline Case definition & $\begin{array}{l}\text { Based upon agreed criteria } \\
\text { (probable), pneumonia based on } \\
\text { clinical diagnosis by an elderly } \\
\text { physician included at least one of } \\
\text { the following symptoms occurring } \\
\text { as change compared with the } \\
\text { former situation, while other } \\
\text { likely diagnoses were excluded: } \\
\text { tachypnea, malaise, confusion, } \\
\text { shortness of breath, cough } \\
\text { (productive or unproductive), } \\
\text { fever }>38^{\circ} \mathrm{C} \text { or fever in the last } \\
48 \text { h, chest pain (respiratory) in } \\
\text { combination with new focal } \\
\text { (unilateral) abnormalities on } \\
\text { auscultation of the lungs }\end{array}$ & $\begin{array}{l}\text { Pneumonia: based on a clinical } \\
\text { diagnosis, i.e. the most probable } \\
\text { diagnosis, by an elderly care } \\
\text { physician (not predefined) }\end{array}$ & $\begin{array}{l}\text { Pneumonia: based on a clinical } \\
\text { diagnosis, i.e. the most probable } \\
\text { diagnosis, by an elderly care } \\
\text { physician (not predefined) }\end{array}$ \\
\hline Data collection & $\begin{array}{l}\text { Aggregated data } \\
\text { Weekly reporting to researchers } \\
\text { Prospective } \\
\text { Several infections }\end{array}$ & $\begin{array}{l}\text { Individual-level data } \\
\text { Reporting directly after } \\
\text { pneumonia diagnosis } \\
\text { Prospective } \\
\text { Focus pneumonia }\end{array}$ & $\begin{array}{l}\text { Individual-level data } \\
\text { Registration directly after } \\
\text { pneumonia diagnosis } \\
\text { Semi-annually reporting to } \\
\text { researchers } \\
\text { Prospective } \\
\text { Several intercurrent health } \\
\text { problems and semi-annually, } \\
\text { health-related items }\end{array}$ \\
\hline Registration & $\begin{array}{l}\text { Weekly count of new cases of } \\
\text { several infections, including } \\
\text { (probable) pneumonia, which } \\
\text { were reported in a web-based } \\
\text { system }\end{array}$ & $\begin{array}{l}\text { Reporting on a continuous basis of } \\
\text { each pneumonia episode, and } \\
\text { additional case data were } \\
\text { collected using a web-based } \\
\text { system }\end{array}$ & $\begin{array}{l}\text { Reporting on a continuous basis } \\
\text { per resident of several intercurrent } \\
\text { health problems, including } \\
\text { pneumonia, using paper } \\
\text { questionnaires }\end{array}$ \\
\hline
\end{tabular}


conducted from 2012 until 2015 [24]. The aim of this study was to develop and assess the effects of a practical guideline for optimal symptom relief following the diagnosis of pneumonia in nursing home residents with dementia. Pneumonia was the only diagnosis assessed and based on a clinical diagnosis by an elderly care physician. It was directly reported at diagnosis. Data were collected at the patient level from the starting date of the pneumonia.

The third study was the DEOLD (Dutch End of Life in Dementia) study, which was conducted from 2007 until 2011 [23]. In this study, newly admitted nursing home residents with dementia were followed until death or conclusion of the study; pneumonia was one of several health problems assessed to describe the patient's condition. Pneumonia was assessed until July 2010 as a clinical diagnosis by an elderly care physician, and it was recorded directly upon diagnosis.

In national surveillance, data on influenza vaccination were collected using an annual questionnaire covering the entire influenza season. On average, $95 \%$ of residents in the nursing homes participating in national surveillance are vaccinated [4]. In the DEOLD study, 53\% (198/372) of residents definitely received influenza vaccination before nursing home admission or within 8 weeks after admission, but the elderly care physician had no access to data about previous vaccination or did not complete the item in $29 \%$ (108/372) of cases, while the physician reported there was no vaccination for $18 \%(66 / 372)$. In subsequent semi-annual assessments, there were few missing values, and between $81 \%$ and $91 \%$ received the vaccination. In the PneuMonitor trial, no data were collected concerning influenza vaccination. Regarding antibiotic treatment, in the PneuMonitor trial, in $87 \cdot 1 \%$ of cases, the patient received antibiotics [24]. In the DEOLD study, this was $82.9 \%(136 / 164)$. In national surveillance, no data were collected on treatment with antibiotics.

\section{Incidence calculations}

With national surveillance overlapping the time periods of the DEOLD study and the PneuMonitor trial, the incidence of pneumonia as calculated based on these three studies were compared. Based on each study, a yearly pneumonia incidence was calculated per 1000 psychogeriatric beds with a $95 \%$ confidence interval $(\mathrm{CI})$. The incidence was calculated by dividing the total number of new pneumonia events by the total number of beds or residents being monitored in that year. For reason of accuracy, calculations were performed with three decimal places. For the national surveillance and the PneuMonitor trial, data about pneumonia events were collected per nursing home facility, for all residents in the participating nursing homes during the study period. Not all nursing homes participated the entire study period and the same length of time. Therefore, incidence was calculated by taking into account the number of beds per year with zero beds for the time period nursing homes did not participate. The total number of beds was based on the reported number of beds while assuming $100 \%$ occupancy (a realistic assumption as occupancy in the Netherlands is close to $100 \%$ ). For the DEOLD study, the total number of beds corresponds to the actual number of participants and the duration of time they participated in the study.

\section{Correction factor for comparability of incidence figures}

The PneuMonitor trial and the DEOLD study both resulted in an incidence per psychogeriatric bed, as nursing homes with psychogeriatric wards only (residence of mainly those with dementia) participated. In national surveillance, however, nursing homes with a mixture of psychogeriatric wards and somatic wards participated as well. Therefore, incidence of the national surveillance was not directly comparable to the incidence per psychogeriatric beds, and a correction factor was needed. This correction factor was calculated based on data from nursing homes that participated in national surveillance from 2009 to 2015 , and separately reported for psychogeriatric beds and somatic beds. The incidence of pneumonia in psychogeriatric beds was compared with the incidence in nursing homes with only somatic beds per 1000 beds per week over the 7-year study period. If the incidence of pneumonia in psychogeriatric beds was statistically significantly different with $P<0.05$ from the incidence in somatic beds over the 7-year study period, the 'psychogeriatric bed/somatic bed' incidence ratio was applied as a correction factor to other nursing homes with a mixture of wards. For the mixed nursing homes, the incidence was corrected for the average proportion of psychogeriatric beds for the study period that a nursing home participated. If the proportion of psychogeriatric beds was missing for the complete time period, the nursing home was excluded from this analysis. 
Table 2. Inclusion of nursing homes in three Dutch studies among residents with dementia

\begin{tabular}{|c|c|c|c|}
\hline $\begin{array}{l}\text { Nursing home } \\
\text { characteristic }\end{array}$ & National surveillance [25] & PneuMonitor trial [24] & DEOLD study [23] \\
\hline $\begin{array}{l}\text { Number of nursing } \\
\text { homes }\end{array}$ & $\begin{array}{l}39 \text { different nursing home } \\
\text { organizations covering } 60 \\
\text { facilities }\end{array}$ & $\begin{array}{l}32 \text { nursing homes organizations } \\
\text { covering } 43 \text { facilities }\end{array}$ & $\begin{array}{l}17 \text { nursing home organizations } \\
\text { covering } 28 \text { facilities }\end{array}$ \\
\hline $\begin{array}{l}\text { Number of beds/ } \\
\text { participants }\end{array}$ & $\begin{array}{l}\text { On average } 2745 \cdot 1 \text { beds per year } \\
(2104 \cdot 9-3352 \cdot 4)\end{array}$ & $\begin{array}{l}\text { On average } 1800 \text { beds per year } \\
(887-2707)\end{array}$ & $\begin{array}{l}\text { On average } 131 \cdot 4 \text { participants per } \\
\text { year }(48 \cdot 6-203 \cdot 7)\end{array}$ \\
\hline $\begin{array}{l}\text { Percentage of } \\
\text { psychogeriatric } \\
\text { beds }\end{array}$ & $\begin{array}{l}\text { Range } 0-100 \% \text { with an average } \\
\text { of } 61 \% \text { psychogeriatric beds per } \\
\text { nursing home* }\end{array}$ & $100 \%$ & $100 \%$ \\
\hline $\begin{array}{l}\text { Nursing home } \\
\text { inclusion }\end{array}$ & $\begin{array}{l}\text { Nursing homes with }>50 \\
\text { residents participated on a } \\
\text { voluntary basis and were } \\
\text { recruited among all Dutch } \\
\text { nursing homes (nursing homes } \\
\text { with rehabilitation only were } \\
\text { excluded) }\end{array}$ & $\begin{array}{l}\text { Nursing homes with one or more } \\
\text { psychogeriatric wards were } \\
\text { recruited both on individual } \\
\text { basis and via academic networks } \\
\text { of nursing homes. Recruitment } \\
\text { aimed at nursing homes } \\
\text { participating in the study being } \\
\text { well spread over the } 12 \text { provinces } \\
\text { of the Netherlands }\end{array}$ & $\begin{array}{l}\text { Nursing homes were recruited } \\
\text { purposefully nationwide, aiming } \\
\text { primarily at variability in } \\
\text { outcome, and second, at } \\
\text { representativeness for the nation. } \\
\text { For example, nursing homes were } \\
\text { recruited stratified by province }\end{array}$ \\
\hline
\end{tabular}

* Unpublished data [25], the other nursing home characteristics are described in Haenen et al. [4]

\section{Sub-analyses for comparability inclusion of residents}

The design of the DEOLD study provided the opportunity to compare incidence rates of newly admitted residents with after having lived in the nursing home for a longer period of time. The incidence of pneumonia per 1000 beds per year was calculated for 3-monthly time slots (i.e. 3, 6, 9, and 12 months) following admission to a nursing home to find potential explanations for differences in incidence between the studies as a result of the documented differences in design.

\section{Statistical analyses}

Statistical analyses were performed in SPSS version 22.0 (SPSS Inc, Chicago, Illinois, USA). Incidences were compared using a $95 \% \mathrm{CI}$.

\section{RESULTS}

\section{Studies}

Table 2 describes the characteristics of the included nursing homes in the three studies. The yearly number of included beds was much higher in national surveillance and the PneuMonitor trial than the number of residents followed in the DEOLD study, i.e. 1800 and 2700 vs 131. This results in wide CIs around the incidence based on the DEOLD study. On average, $61 \%$ of the beds in nursing homes participating in the national surveillance study were assigned as psychogeriatric beds, compared with $100 \%$ in the PneuMonitor trial and DEOLD study.

\section{Incidence calculations}

Based on national surveillance data, the overall incidence ranged from $149 \cdot 4$ per 1000 beds in 2011 to 237.5 per 1000 beds in 2014 (Supplement 1). Pneumonia incidence in the national surveillance data was significantly lower in the nursing home with psychogeriatric beds compared with somatic and rehabilitation beds, i.e. $3 \cdot 9(95 \%$ CI $3 \cdot 2-4 \cdot 6)$ compared with $5 \cdot 7(95 \%$ CI $5 \cdot 1-6 \cdot 3)$, and thus the correction factor was calculated and amounted $0 \cdot 7(3 \cdot 9 / 5 \cdot 7)$. When adjusting the national surveillance incidence with this factor for the proportion of psychogeriatric beds, the incidence of pneumonia per psychogeriatric bed was lower and ranged from 78.9 in 2011 to $117 \cdot 1$ in 2010 (Supplement 1). In the PneuMonitor trial, the incidence was similar and ranged from $71 \cdot 0$ in 2015 to $94 \cdot 3$ in 2013. Incidence was calculated using a total number of 599 pneumonia cases among which $135(22 \cdot 5 \%)$ were 'missed' cases enrolled retrospectively. In the DEOLD study, the incidence was clearly higher and ranged from 267.3 in 2007 to 363.2 in 2008 . Within each of the three studies, the yearly incidences were comparable (Fig. 1). In 2009 and 2010 , the incidence in national surveillance was 


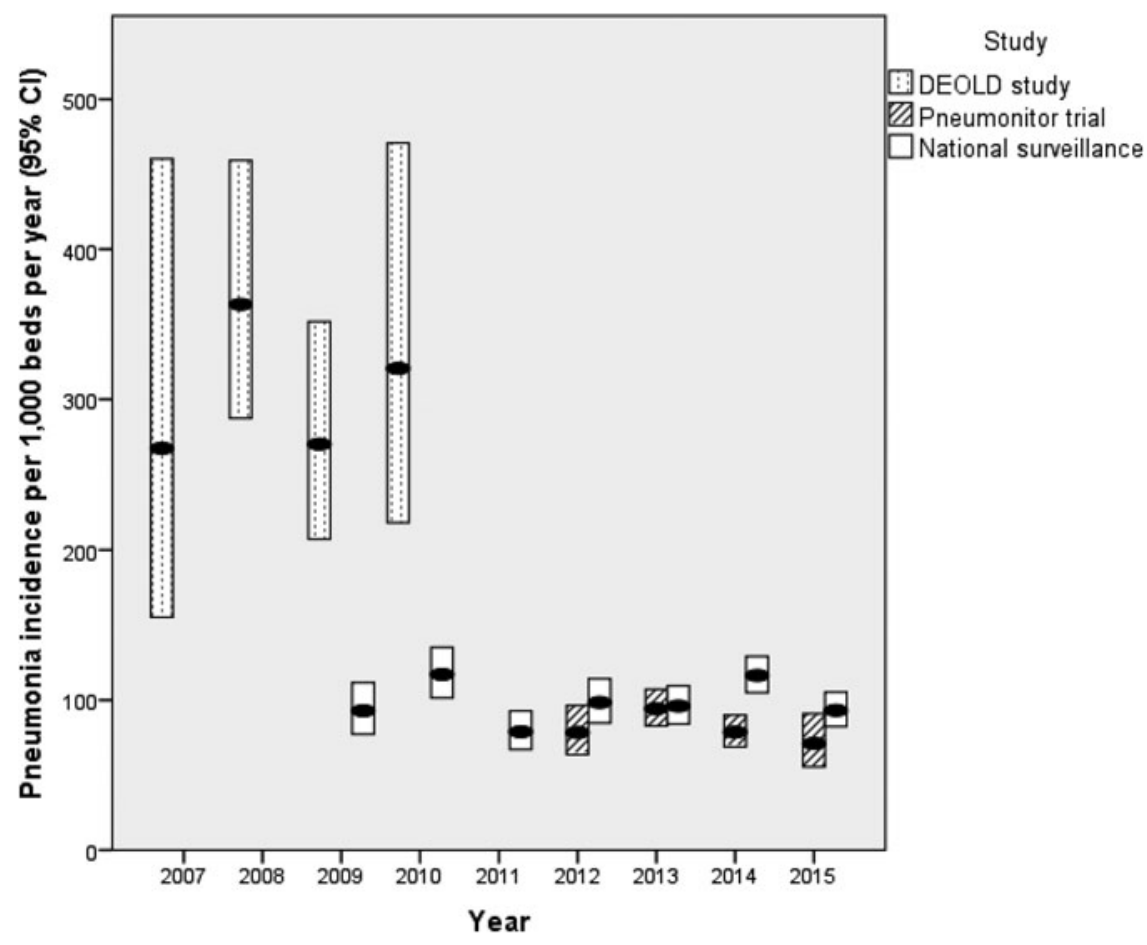

Fig. 1. Pneumonia incidence with $95 \%$ confidence interval in three nursing home studies in 2007-2015.

significantly lower than in the DEOLD study, with the studies showing the same pattern with higher incidence in 2010 than in 2009. The incidence in national surveillance was similar to that in the PneuMonitor trial, except for 2014.

\section{Sub-analyses for comparability of residents across the three studies}

Table 3 shows a significantly higher incidence for newly admitted residents within the first 3 months of their admission, compared with residents who had resided in the nursing home for a longer time.

\section{DISCUSSION}

Estimation of pneumonia incidence over the period 2007-2015 in Dutch nursing home residents with dementia, as assessed based on three different studies, showed that pneumonia occurred frequently in nursing home populations, especially among recently admitted residents. The within-study incidence was remarkably stable and consistent over years. Pneumonia incidence based on Dutch national surveillance data, after correction for the proportion of psychogeriatric beds, and based on the PneuMonitor trial were similar, i.e. about 100 pneumonia events per 1000 beds per year. Remarkably, pneumonia incidence was lower among residents of psychogeriatric wards compared with somatic and rehabilitation wards. The incidence calculated based on data from the DEOLD study was significantly higher compared with the other two studies, whereas the percentage of pneumonia cases receiving antibiotic treatment was in the same order of magnitude, with $83 \%$ in DEOLD vs $87 \%$ in PneuMonitor, respectively.

The PneuMonitor trial previously reported an incidence of 85 episodes of pneumonia per 1000 residents per year [24]. In the pre-intervention phase of the PneuMonitor trial, an overall incidence of 93 pneumonia events per 1000 psychogeriatric beds per year was found [12]. This was comparable with an overall incidence of 95 pneumonia events per 1000 beds per year in a study in 1996-1998 to assess morbidity in nursing home patients with dementia and pneumonia treated with and without antibiotics. This study employed a design that was similar to PneuMonitor trial in many respects, except for the intervention, and also included 'missed' cases of pneumonia retrospectively $[11,12]$. The annual incidence per 1000 psychogeriatric beds in the PneuMonitor trail (ranging from 71 to 94) and the national surveillance (ranging from 79 to 117) are in line with the previously reported incidence, indicating that in a nursing home of 100 
Table 3. Pneumonia incidence following admission of a nursing home resident with dementia in the DEOLD study

\begin{tabular}{lllll}
\hline \hline Months after admission & Number of pneumonia events & Number of beds/year & Incidence/1000 beds/year & $95 \%$ CI \\
\hline $0-3$ & 36 & $86 \cdot 3$ & $417 \cdot 1$ & $300 \cdot 8-578 \cdot 2$ \\
$3-6$ & 20 & $75 \cdot 2$ & $265 \cdot 8$ & $171 \cdot 5-412 \cdot 0$ \\
$6-9$ & 21 & $66 \cdot 1$ & $317 \cdot 8$ & $207 \cdot 2-487 \cdot 4$ \\
$9-12$ & 10 & $60 \cdot 2$ & $166 \cdot 0$ & $89 \cdot 3-308 \cdot 5$ \\
\hline \hline
\end{tabular}

residents with dementia about 10 cases of pneumonia are to be expected per year. The incidence based on the DEOLD study was much higher (range 267363 ), which would implicate over 25 cases of pneumonia per year in a nursing home of 100 residents with dementia.

The higher incidence in the DEOLD study compared with national surveillance may be explained in part by the fact that in the DEOLD study, only newly admitted residents were included. This could implicate increased susceptibility to infectious respiratory tract infections in this group of newly admitted patients due to, e.g. going through a stressful life event, which may affect the immune system. Such effects were found previously after stressful life events, such as change of health status and living apart from spouse [28].

A second biological explanation is that newly admitted residents might be at higher risk due to increased susceptibility to the pathogens specifically present in the new environment they are settling into. A comparable pattern has been observed in child day care centers, where children aged $0-2$ years were at higher risk for acquiring influenza-like illness than children aged 2-4 years, and starting child day care in the past 6 months influenced the risk of diarrheal illness [29]. Another possibility is that the recently admitted residents are more closely followed by staff and family. In national surveillance, all residents were monitored irrespective of the time period they were admitted. However, our observation that pneumonia incidence was highest in the first 3 months after admission suggests that newly admitted residents might be at higher risk for acquiring pneumonia than those who have resided in the nursing home for a longer period. It is noteworthy that the CIs in the DEOLD study were wider due to a lower numbers of patients monitored.

We did not expect to find lower pneumonia incidence in residents of psychogeriatric wards, compared with somatic wards, given that pneumonia-associated mortality is generally considered to be higher in dementia patients compared with other older people where cardiovascular disease and neoplasms are more common causes of death [7, 13]. Moreover, aspiration pneumonia is more likely to occur in dementia patients due to dysphagia, which is a sequela more frequently seen in this group of patients [13]. A previous Dutch nursing home study reported similar pneumonia prevalence in psychogeriatric, somatic, and rehabilitation wards, respectively $21 \cdot 3 \%, 19 \cdot 0 \%$, and $23.2 \%$ [19]. It is possible that, because pneumonia-associated mortality is higher in patients with dementia than in patients without [13], similar prevalence implies a higher incidence in dementia due to censored data as a result of this difference in life expectancy [13]. On the other hand, it is possible that the incidence of pneumonia is truly lower in this patient group, especially when it is compared with other infectious diseases. Patients with dementia are more likely to stay in closed wards, decreasing their chance of encountering airborne infectious pathogens. Their reliance on care may increase their risk of other infectious diseases, such as urinary tract infections or gastroenteritis [30]. Although the difference observed in our comparison was based on data from one nursing home organization only, it must be noted that findings were based on data from a prolonged period of time, and supported in other studies $[31,32]$.

The absence of confirmation by X-ray in nursing homes in the Netherlands resulted in incidence of probable instead of confirmed pneumonia in the three studies, and therefore the 'true' incidence of confirmed pneumonia might be lower. In addition, due to the absence of microbiological testing, the etiological agent remained unknown, which possibly complicated distinguishing aspiration pneumonia from pneumonia with an initial infectious cause. Relying on the diagnosis of probable pneumonia without confirmation may have resulted in differential underdiagnoses in psychogeriatric compared with somatic patients, due to differences in observing symptoms between these two groups of patients. Future research 
should compare incidence in patients with dementia to incidence in patients with no dementia, adjusted for frailty and other diseases which also confer an increased mortality risk. This is relevant because pneumonia with high case fatality is being conceptualized as inherent to the terminal phase of dying from dementia.

Our comparison suggests that the estimated pneumonia incidence is not affected by registration burden. In PneuMonitor, one HAI was registered, whereas in national surveillance, four HAIs were registered. In the PneuMonitor trial, the workload was also lower when not registering pneumonia in case of doubt, which might introduce bias toward under-reporting. On the other hand, in the PneuMonitor trial, pneumonia cases had to be reported to the researcher at the time of diagnosis, minimizing the introduction of recall bias. The fact that the incidence was similar in PneuMonitor and national surveillance suggests that registration burden and recall bias were not major issues and that weekly reporting may suffice, and pneumonia incidence can be consistently assessed in studies either focusing on multiple health items, or only one. In all three studies, the case definition followed routines in medical practice, in order to minimize the registration burden. For national surveillance, specific consensus criteria were developed in collaboration with elderly care physicians [4]. These findings would implicate generalizability to healthcare systems in other countries, given that definitions are often based on clinical symptoms. If the underlying mechanism for higher incidence among newly admitted residents is a biological one, this mechanism would be comparable in other countries as well. For international comparison, harmonization of definitions would be a prerequisite given the differences in healthcare systems. This was successfully done in point prevalence measurements in international studies performed in Europe in 2010 and 2013 [3, 20].

For the surveillance study, we could compare pneumonia incidence to incidence of influenza-like illness, but there was no clear pattern of possible association, with lower influenza incidence in years 2010 and 2011 than in years 2009 and 2012. This may be due to the fact that we assessed incidence per calendar year, and influenza commonly peaks in winter involving two calendar years. The seasonal pattern of pneumonia incidence in nursing homes in a previous study has been reported to be similar to influenza with a peak in the winter months involving two calendar years [33]. The collection of data regarding health problems in the DEOLD study ended in July 2010 and the PneuMonitor trial concluded in April 2015. Therefore, comparison of incidences in 2010 and 2015 is hampered because of the different time periods of data collection and seasonal interference. For some years, comparison is possible, and the DEOLD study and national surveillance showed a similar annual pattern, i.e. the incidence in 2009 was lower than in 2010.

In conclusion, incidence measured among only newly admitted residents may result in higher figures but also higher uncertainties due to a lower numbers of cases monitored. Therefore, in the context of generating national incidence figures, a system following all residents in a nursing home collectively may be the most efficient way to monitor the pneumonia incidence. Lower pneumonia incidence among residents of psychogeriatric wards (almost all dementia) compared with somatic (for people with physical handicaps) needs further study. Nevertheless, our data suggest that residents with dementia, especially when newly admitted, could benefit from infection control measures and/or close monitoring of staff to avoid development of pneumonia or timely diagnose it.

\section{SUPPLEMENTARY MATERIAL}

The supplementary material for this article can be found at https://doi.org/10.1017/S0950268817001339.

\section{ACKNOWLEDGEMENTS}

The authors are grateful to all the nursing homes for their participation in the three studies.

\section{DECLARATION OF INTEREST}

None.

\section{REFERENCES}

1. Strausbaugh LJ. Emerging health care-associated infections in the geriatric population. Emerging Infectious Diseases 2001; 7: 268-271.

2. Koch AM, et al. Severe consequences of healthcare-associated infections among residents of nursing homes: a cohort study. Journal of Hospital Infections 2009; 71: 269-274.

3. European Centre for Disease Prevention and Control. Point Prevalence Survey of Healthcare-Associated Infections and Antimicrobial Use in European Long-Term Care Facilities. April-May 2013. Stockholm: ECDC, 2014. 
4. Haenen A, et al. Surveillance of infections in nursing homes in the Netherlands, a systematic survey is feasible. International Journal of Infection Control 2014; v10: i4.

5. van Buul LW, et al. Antibiotic prescribing in Dutch nursing homes: how appropriate is it? Journal of the American Medical Directors Association. 2015; 16: 229-237.

6. Kammoun S, et al. Immediate causes of death of demented and non-demented elderly. Acta Neurologica Scandinavica Supplementum 2000; 176: 96-99.

7. Brunnstrom HR, Englund EM. Cause of death in patients with dementia disorders. European Journal of Neurology 2009; 16: 488-492.

8. Attems $\mathbf{J}$, et al. Cause of death in demented and non-demented elderly inpatients; an autopsy study of 308 cases. Journal of Alzheimer's Disease 2005; 8: $57-62$.

9. Magaki S, et al. Comorbidity in dementia: update of an ongoing autopsy study. Journal of the American Geriatrics Society 2014; 62: 1722-1728.

10. Keene $\mathbf{J}$, et al. Death and dementia. International Journal of Geriatric Psychiatry 2001; 16: 969-974.

11. van der Steen JT, et al. Pneumonia: the demented patient's best friend? Discomfort after starting or withholding antibiotic treatment. Journal of the American Geriatrics Society 2002; 50: 1681-1688.

12. van der Maaden T, et al. Prospective observations of discomfort, pain, and dyspnea in nursing home residents with dementia and Pneumonia. Journal of the American Medical Directors Association 2016; 17: 128-135.

13. Foley NC, Affoo RH, Martin RE. A systematic review and meta-analysis examining pneumonia-associated mortality in dementia. Dementia and Geriatric Cognitive Disorders 2015; 39: 52-67.

14. Mitchell SL, et al. The clinical course of advanced dementia. New England Journal of Medicine 2009; 361: $1529-1538$.

15. van der Steen JT, Meuleman-Peperkamp I, Ribbe MW. Trends in treatment of pneumonia among Dutch nursing home patients with dementia. Journal of Palliative Medicine 2009; 12: 789-795.

16. Hendriks SA, et al. Dying with dementia: symptoms, treatment, and quality of life in the last week of life. Journal of Pain and Symptom Management 2014; 47: 710-720.

17. van der Steen JT, et al. Physicians' perceptions of suffering in people with dementia at the end of life. Palliative \& Supportive Care 2016: 1-13. doi:10.1017/ S1478951516000985.

18. Eilers R, et al. Prevalence and determinants associated with healthcare-associated infections in long-term care facilities (HALT) in the Netherlands, May to June
2010. Eurosurveillance 2012; 17: pii=20252. Available online: http://www.eurosurveillance.org/ViewArticle. aspx?ArticleId=20252.

19. Eikelenboom-Boskamp A, et al. Three-year prevalence of healthcare-associated infections in Dutch nursing homes. Journal of Hospital Infections. 2011; 78: 59-62.

20. European Centre for Disease Prevention and Control. Point Prevalence Survey of Healthcare-Associated Infections and Antimicrobial Use in European Long-Term Care Facilities. May-September 2010. Stockholm: ECDC, 2014.

21. Janssens JP, Krause KH. Pneumonia in the very old. Lancet Infectious Diseases 2004; 4: 112-124.

22. El-Solh AA, et al. Etiology of severe pneumonia in the very elderly. American Journal of Respiratory and Critical Care Medicine 2001; 163: 645-651.

23. van der Steen JT, et al. Retrospective and prospective data collection compared in the Dutch End Of Life in Dementia (DEOLD) study. Alzheimer Disease and Associated Disorders 2014; 28: 88-94.

24. van der Maaden T, et al. Improving comfort in people with dementia and pneumonia: a cluster randomized trial. BMC Medicine 2016; 14: 116.

25. Haenen A, et al. The impact of seven years infection surveillance in a network of Dutch nursing homes. Submitted work.

26. Furman CD, Rayner AV, Tobin EP. Pneumonia in older residents of long-term care facilities. American Family Physician 2004; 70: 1495-1500.

27. Muder RR. Pneumonia in residents of long-term care facilities: epidemiology, etiology, management, and prevention. The American Journal of Medicine 1998; 105: 319-330.

28. Phillips AC, et al. Stressful life events are associated with low secretion rates of immunoglobulin A in saliva in the middle aged and elderly. Brain, Behavior, and Immunity 2006; 20: 191-197.

29. Roberts L, et al. Effect of infection control measures on the frequency of diarrheal episodes in child care: a randomized, controlled trial. Pediatrics 2000; 105: 743-746.

30. Heijne JC, et al. Quantifying transmission of norovirus during an outbreak. Epidemiology 2012; 23: 277-284.

31. Eriksen HM, Iversen BG, Aavitsland P. Prevalence of nosocomial infections and use of antibiotics in longterm care facilities in Norway, 2002 and 2003. Journal of Hospital Infections 2004; 57: 316-320.

32. Magaziner J, et al. Mortality and adverse health events in newly admitted nursing home residents with and without dementia. Journal of the American Geriatrics Society 2005; 53: 1858-1866.

33. Van der Steen JT, et al. Incidentie van pneumonie bij Nederlandse verpleeghuisbewoners met dementie. Infectieziekten Bulletin 2003; 14: 126-132. 